2011

\title{
Strategic Research Planning in a Law School Setting
}

Lisa Philipps

Osgoode Hall Law School of York University, lphilipps@osgoode.yorku.ca

Follow this and additional works at: http://digitalcommons.osgoode.yorku.ca/all_papers

\section{Repository Citation}

Philipps, Lisa, "Strategic Research Planning in a Law School Setting" (2011). All Papers. Paper 20.

http://digitalcommons.osgoode.yorku.ca/all_papers/20 


\title{
Strategic Research Planning in a Law School Setting
}

\author{
Lisa Philipps ${ }^{1}$ \\ Osgoode Hall Law School, York University \\ Toronto, Canada
}

\begin{abstract}
$\underline{\text { Abstract }}$
Strategic planning processes are by now familiar in many Universities and law faculties. Most often these operate at the highest level of generality and are aimed at articulating an institution's overall strengths, direction and priorities for growth or improvement. The tools of strategic planning can also be deployed to focus attention on a specific dimension of a law school's profile such as its research mission. This short paper will describe the effort to develop a strategic research plan at Osgoode Hall Law School, and will share experience about the challenges and potential benefits of such an enterprise.
\end{abstract}

$\underline{\text { Introduction }}$

Osgoode Hall Law School was established in 1889 and is the oldest and largest common law program in Canada. Strategic planning tools have been in use at Osgoode since at least the late 1990s. However 2009 saw the first efforts to develop a sub-plan focusing specifically on the law school's research mission. An important part of the context was that an extensive review and reform of the curriculum was nearing completion at that point. While the content and design of the curriculum had been debated for decades, the faculty decided in 2005 to make a serious push to implement reforms. This was reflected in the law school's overall strategic plan for 2006-10 which included commitments to reform the LL.B. (since renamed J.D.) curriculum, to establish a Standing Committee on Teaching and Learning, and to create the Osgoode Course Design Institute, an annual two-day intensive workshop on pedagogy. The stated goal was to create a "more engaged learning community" and to establish Osgoode as "a North American leader in the development and implementation of active learning strategies in legal education at both the undergraduate and graduate levels." ${ }^{2}$ Since the adoption of that plan and through the efforts of several Curriculum Reform Working Groups the faculty has succeeded in approving significant changes to both its first year and upper year programs, some of which are still in the process of being implemented. ${ }^{3}$

\footnotetext{
${ }^{1}$ Professor and Associate Dean (Research, Graduate Studies \& Institutional Relations). This short paper was prepared for the International Association of Law Schools (IALS) meeting at the University of Buenos Aires, April $13-15,2011$. The views expressed are my personal reflections as the faculty member charged with leading the recent research planning exercise at Osgoode. Please send comments to Iphilipps@osgoode.yorku.ca.

${ }^{2}$ Osgoode Hall Law School, Plan for the Law School 2006-10: Making a Difference, at 3 (online at http://www.osgoode.yorku.ca/about/documents/plan for the law school 2006-2010.pdf).

${ }^{3}$ In the first year program these include creation of a new mandatory course in Ethical Lawyering in a Global Community; more thorough integration of research, writing and dispute resolution skills into the Legal Process course; new requirements for students to receive written feedback from professors and to receive instruction on how to write a scholarly paper; and a greater emphasis on critical and interdisciplinary perspectives. In the upper year program the faculty has recently approved the creation of a "praxicum" requirement for all students to take at least one clinical, intensive or seminar course that focuses on integrating theory and practice, and to complete a third year paper to assist in developing advanced research and writing skills. Additionally, all students must complete the Osgoode Public Interest Requirement (OPIR) in order to graduate. This is a unique program in Canada and consists of 40 hours of unpaid public interest law-related work, followed by a reflective exercise in the
} 
With curriculum reforms well advanced and as the 2006-10 strategic plan neared the end of its term, the time was considered ripe to bring a similar level of institutional focus to reviewing and strengthening the research mission. Osgoode has a long-standing reputation and self-image as a research intensive law school with pluralistic strengths in doctrinal, legal theoretical and socio-legal scholarship. However there was a broad sense that the internal and external environment for legal research was changing in ways that called for serious reflection about how best to position ourselves for continued success on this front. Internally, the collective commitment to pedagogical and curricular innovation had generated excitement but also questions about how faculty could best balance and integrate their teaching and research. Externally, we were hearing frequently from governments, granting agencies, and central university administrators about accountability, performance indicators, international reputational measures, and differentiation of more and less research intensive institutions within Canada. ${ }^{4}$ It seemed timely to conduct an in-depth review of our research profile both to meet external demands for information about our productivity and standing, and to inform internal discussions about how best to support and develop the research culture of the law school.

The research planning exercise of 2009-11 has been organized around the following elements which developed not in chronological sequence but iteratively:

- Articulating a vision about how we define ourselves as a research institution

- Taking stock of current strengths and challenges

- Setting priorities and goals for improvement

- Identifying strategies for advancement

- Establishing a process and timelines for evaluating progress

In the balance of this short paper I will expand briefly on each of these components, our process for tackling them, and some tentative lessons learned.

\section{Articulating a vision}

This is the most difficult piece of strategic planning, in my humble view. It involves bringing to the surface the deeply held but often unstated commitments and identity of a community, and setting a future direction that will refresh and re-energize the institutional project without excessive rupture from or devaluation of its past trajectory. The vision must enjoy wide buy-in internally while also appealing to external constituencies. It must be inclusive while also coming to terms with choices about what aspects of the law school need to be in the foreground at a particular time in its history. There is no substitute here for collegial conversation. At Osgoode the articulation of a research vision began early in the process and has centred on our identity and reputation as a research intensive law school, committed to maximizing the visibility and influence of our work, and with overarching strengths in legal and socio-legal theory, transnational legal studies, law and social justice/equality, and business

\footnotetext{
form of a short essay or 3-hour group discussion facilitated by a faculty member or practitioner. More information is available on at www.osgoode.yorku.ca. For brief overviews see Lisa Philipps, "Robust Support for First-Year Curriculum Reforms", Continuum 2007, p.22; Colleen Hanycz, "Pursuing Best Practices in Legal Education", Continuum 2007, p.23; and Christine Ward, "Raising Ethical Lawyers" Continuum 2008, p.8 (all online at http://www.osgoodealumni.ca/keep-in-touch/continuum-magazine/).

${ }^{4}$ See George Fallis, Multiversities, Ideas and Democracy (University of Toronto Press, 2007), for an in-depth analysis of changes to the social contract in relation to universities in Canada.
} 
regulation. The process has also identified important sub-strengths and emerging strengths that are ripe for growth and development.

\section{Taking stock of strengths and challenges}

Osgoode like any law school has a proud if vague sense of its own historical and current standing as a research instituton. The task of the planning exercise was to test these perceptions against available evidence and to obtain as far as possible a clearer and more detailed picture of our performance and reputation vis a vis our own aspirations and that of other law schools we admire.

In an effort to get beyond anecdotal evidence of successes and challenges, the Research Office undertook a study of quantitative research indicators. The choice of what indicators to study was limited to some degree by available data and by the need for realism about how much staff time could be devoted to quantitative analysis. However, in order for the study results to be credible and to provoke anything more than a critique of the study itself, it was important to look at as many different indicators as possible and to explain why each could tell us something worth knowing. Careful methodological design was also important, as well as candour about the shortcomings of different data sources drawing in part on academic literature about the use of bibliometrics to assess research performance. To date we have gathered and analyzed data about the following indicators and features of the law school research environment. In every case we have attempted to develop a comparative picture of how Osgoode has performed over time, or relative to other law schools in Canada or internationally.

- Total external funding for faculty research in each of the previous 6 years, and the proportionate importance of different sources of external funding

- Total funding from the Social Sciences and Humanities Research Council of Canada (SSHRC) in each of the previous 6 years: SSHRC is our most important source of research funding quantitatively, and also because proposals are peer reviewed such that grant success is an independent measure of quality and reputation.

- Number of applications for SSHRC funding in recent years, and success rates

- Average per capita SSHRC funding compared to other Canadian law schools in the previous two years: This was compared to data collected in the mid-1990s about our relative success in obtaining SSHRC grants.

- Number of Canada Research Chairs (CRCs) compared to other law schools: CRCs bring additional public funding and research profile to the university.

- Number of Canada Foundation for Innovation (CFI) grants compared to other law schools: CFI provides major grants for research infrastructure including building construction and information technology.

- Number of funded large team research projects led by Osgoode faculty

- Student-faculty ratios

- Policies on research release time, compared to policies we could determine at other Canadian law schools

- External rankings of faculty quality in Canadian law schools based on citations of scholarship internationally (as published in MacLean's Magazine)

- SSRN download rankings internationally

- Citations of Canadian law school faculty scholarship historically and since 2006, using two electronic periodical databases (HeinOnline and LexisNexis) 
- Publication counts as self-reported by faculty for the previous 6 years

- Number of journal articles published by faculty at Canadian law schools in the previous three years, based on searches in three electronic periodical databases (LegalTrac, HeinOnline, and LexisNexis)

- Citations of academic scholarship by the Supreme Court of Canada

- Number and focus of research centres compared to other leading law schools

Study results were presented to faculty for discussion as they became available, sometimes leading to additional research as colleagues identified gaps in the data or other indicators they would like to examine. While recognizing that the data are inevitably partial and incomplete no matter how many sources are mined, the study did help to galvanize a commitment to critical self-evaluation and improvement where needed. My sense is that while faculty rightly remain skeptical about the ability of crude numerical measures to capture the true quality of a law school's scholarly contributions, looking at the numbers has created a greater awareness that we must be ready to point others to specific evidence of our strengths, as well as some insights about how best to deploy available resources.

A final observation is that "taking stock" in the way we did was time consuming and required sustained effort by the Associate Dean and several staff and students over a period of months. Now that a baseline has been laid, it is hoped that updating the study periodically will be less time consuming.

\section{Setting priorities and identifying strategies for advancement}

The main benefit of analyzing research data, as discussed above, was to focus attention on our performance and standing as a research intensive law school. A sense of priorities emerged partly from the data but also through collegial discussion about the factors that have helped individual scholars to succeed, what is felt to be distinctive and compelling about Osgoode's research culture, and what other law schools were doing to promote research and build their reputations. Smarter dissemination and communication of research through a range of media, and to a range of audiences, was identified as a key. Likewise, community consultation revealed an appetite for greater integration of both undergraduate and graduate students into the research and publishing culture of the law school. The agreed upon need to sustain high levels of institutional support for research led to a productive discussion about what supports may be most important to develop or expand in the near term.

Priority setting necessarily involves the integration of research goals with the law school's broader strategic plan, not just to confront trade-offs but also to identify synergies. Perhaps the best example relates to the size and mix of the faculty complement which is a key not only to advancing the research mission but to all aspects of the law school. The research sub-plan is currently being fed into the process of writing a new overarching plan for Osgoode, scheduled for completion in 2011.

I have found that it is not difficult to identify different strategies for advancing research priorities. ${ }^{5}$ The more difficult task is to decide how to begin and where to devote limited time and resources. The least

\footnotetext{
${ }^{5}$ Note there is some great literature, especially in the U.S., about strategies that some law schools have tried to encourage and strengthen research. See for example James Lindgren, "Fifty Ways to Promote Scholarship" (1999) 49 J. of Legal Ed. 126; James Lindgren, “Is Blogging Scholarship? Why Do You Want to Know?” (2006) 84 Wash. U.
} 
expensive and possibly most effective strategy we have deployed thus far is simply to talk about the research mission more often. Including research reports on the agenda for faculty meetings, running faculty development sessions about how to publish and otherwise increase the international readership for their work, celebrating individual and institutional successes, and hosting meetings that include students in strategic planning discussions about research are all useful strategies for advancing priorities in this area. Aside from the actual substantive content of such meetings, they send important signals about what is valued and what kinds of contributions will be recognized as significant. Community members are generally so attuned to the signals of institutional leaders that just talking about things can generate a surprising amount of momentum. Presenting the data on research indicators served as a springboard to engage people in a conversation about their priorities and needs. This led to a number of follow up initiatves, some of which are worth highlighting.

Two working lunch sessions garnered particular interest and follow up activity among faculty and graduate students. The first was a presentation by four law book publishers, each with their own kind of market niche and advice about how and where to publish a dissertation or other monograph. The second was a forum on scholarly blogging, led by several innovative social media users from our own faculty. ${ }^{6}$

In terms of concrete supports the Research office reallocated some of its budget to provide a small Research Development Grant for those who apply unsuccessfully for external funding. The purpose is to provide some recognition for effort expended, and to fund student research assistance or other costs incurred to rework and improve the application. In addition, we have reinforced in various ways the message that access to internal funding or supports will be based in part on whether the faculty member has made efforts to obtain an external grant. Staff in the Research Office provide assistance in completing some elements of grant applications, such as updating of cv's in the format required by the granting agency. The Associate Dean reviews and provides comments on draft proposals, and arranges for other faculty with cognate expertise to provide comments as well. A student was hired to provide year-round hands-on support to faculty to manage their SSRN and other web postings.

We took some steps to boost research communications through a new alumni e-brief feature called Osgoode Knowledge: Research \& Ideas that profiles a single recent publication with current policy relevance, ${ }^{7}$ a web page devoted to graduate student research achievements, ${ }^{8}$ and renewed efforts to alert relevant media and outside constituencies to new books, important conferences, and law reform activities of the faculty.

L. Rev. 1105; and Joseph P. Tomain and Paul L. Caron, "Associate Dean for Faculty Research Position: Encouraging and Promoting Scholarship" (2001-2002) 33 U. Tol. L. Rev. 233.

${ }^{6}$ The Forum can be viewed here: http://www.osgoode.yorku.ca/research/research ideas.html.

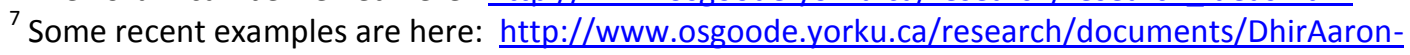
Winter2011.pdf, http://www.osgoode.yorku.ca/research/documents/ScottDayna-Winter2011.pdf, http://www.osgoode.yorku.ca/research/documents/LawrenceSonia-Winter2011.pdf

${ }^{8}$ http://www.osgoode.yorku.ca/research/grad news.html 
At a more fundamental level the Associate Dean and Dean's offices have worked to promote a sense of intellectual community and shared investment in the research culture. This includes supporting (with a catering budget and our own active involvement) a healthy faculty seminar series in which colleagues discuss and receive feedback on their own work. Two intensive joint workshops with a partner law school in India also gave our own faculty a chance to learn about each other's current work and to delve into some common literatures and interests.

\section{Process and timelines for evaluating progress}

My experience at Osgoode suggests that the process of creating a research plan has value in itself. However this value may be short lived without a commitment to implementation over a time period and monitoring of progress. Developing these final elements will require further investments of time and energy in future. The study of quantitative indicators will be updated during the summer of 2011, hopefully providing some evidence of growth. But the more important evidence will lie in less tangible realms, such as our ability to attract and retain top faculty from around the world, our scholarly reputation generally and in particular fields, and the ability of our research to impact the development of knowledge and ideas inside and outside the academy. 